\title{
Ñande Ru Marangatu: a judicialização da luta pela terra indígena e o papel do cientista*
}

\section{Nande Ru Marangatu: the judicialization of the struggle for indigenous land and the role of the scientist}

\author{
Thiago Leandro Vieira Cavalcante \\ Doutorando pelo Programa de Pós-graduação em História da Faculdade de Ciências \\ e Letras de Assis/Universidade Estadual Paulista \\ Rua Ciro Melo, 3880 \\ 79830-050 - Dourados - MS - Brasil \\ thiago_cavalcante@hotmail.com
}

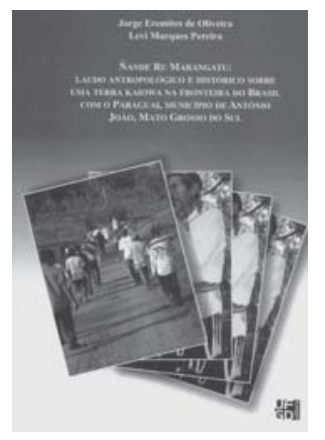

EREMITES DE OLIVEIRA, Jorge; PEREIRA, Levi Marques. Ñande Ru Marangatu: laudo antropológico e histórico sobre uma terra kaiowa na fronteira do Brasil com o Paraguai, município de Antônio João, Mato Grosso do Sul.

Dourados: Editora UFGD. 2009. 282p.
N $\begin{aligned} & \text { a obra apresentada os autores trazem a público o laudo pericial } \\ & \text { de natureza antropológica e histórica elaborado em aten- }\end{aligned}$ dimento à determinação feita pelo juízo da 1a Vara da Justiça Federal de Ponta Porã, Mato Grosso do Sul. Tal perícia foi solicitada para compor os autos do litígio judicial, no qual os proprietários de terras incluídas no perímetro identificado e delimitado como terra indígena em processo administrativo conduzido pela Fundação Nacional do Índio (Funai) e, posteriormente, demarcadas pelo Ministério da Justiça e homologadas pelo presidente da República, contestam a demarcação da Terra Indígena Nande Ru Marangatu, no município de Antônio João. Trata-se de uma área na fronteira entre Brasil e Paraguai, identificada e delimitada pela Funai como sendo de ocupação tradicional de uma comunidade indígena, que recebe o mesmo nome da área em questão e pertence à etnia kaiowa.

Os Kaiowa são falantes da língua guarani. Estima-se que sua presença na região do atual estado de Mato Grosso do Sul e também no Paraguai, onde são denominados Pai Taviterã, remonte ao período pré-colonial. Provavelmente são descendentes dos chamados Itatim, missionados pelos jesuítas durante o século XVII. Após o término

da empresa jesuítica, foram novamente contatados em 1754, por ocasião dos trabalhos demarcatórios de fronteira em atendimento ao disposto no Tratado de Madri. Durante o século XVIII e até a Guerra do Paraguai contra a Tríplice Aliança (1864-1870), sofreram pouca interferência do mundo não indígena. Essa situação começou a mudar quando, ao final da guerra, o Estado brasileiro achou importante povoar a região com não índios. Desse período até a década de 1940 predominou, na região, a exploração comercial de ervais nativos, responsáveis por uma imensa fatia da produção mundial de erva-mate (Ilex paraguariensis). Por meio de arrendamento de terras públicas a Companhia Mate Larangeira estabeleceu um grande monopólio, apoiado por forte influência política. ${ }^{1}$ Durante esse período o impacto sobre a situação territorial dos Kaiowa foi menor, pois como o interesse 
da empresa estava nos ervais, não havia grandes empreendimentos de derrubada das matas nativas, locais preferidos pelos indígenas para o estabelecimento de seus assentamentos. Além disso, era frequente a utilização do braço indígena como mão de obra no manejo da erva.

Com a ascensão de Getúlio Vargas a partir de 1930, o Estado brasileiro passou a priorizar a nacionalização das fronteiras, e, assim, os contratos com a Companhia Mate Larangeira não foram mais renovados, pois a origem de seu idealizador era a Argentina. A política estatal caminhou no sentido de promover a intensificação do povoamento não índio, naquele que chamou de "espaço vazio". Nesse contexto, o território kaiowa foi declarado terra devoluta e distribuído a não índios, encarregados de implantar fazendas destinadas a atividades agropastoris.

Foi então que a comunidade indígena Ñande Ru Marangatu viu, primeiro, pequenos posseiros e, depois, grandes proprietários tentarem apoderar-se de suas terras. Os primeiros, com poucos recursos, foram motivadores de tensões, mas não capazes de expulsá-la; já os segundos, com grande poderio, utilizaram vários artifícios, incluindo a violência, para desalojar os indígenas e até mesmo os pequenos posseiros que chegaram anteriormente. Diante de tal situação, aqui relatada de maneira breve e incompleta, surgiu o litígio no qual a perícia solicitada pelos autores foi inserida.

Após longo período da ocorrência dos fatos e da resistência e mobilização da comunidade, a Funai, atendendo à determinação constitucional, identificou e delimitou a área como terra indígena. Na sequência, o processo de demarcação foi aberto no Ministério da Justiça, que demarcou a área e o encaminhou para homologação, ato realizado pelo presidente da República. Tais atos administrativos motivaram a contestação judicial por parte dos proprietários atingidos pelas medidas administrativas, o que resultou em contestação judicial, à qual a perícia se integra.

Um trabalho dessa natureza não se apresenta no formado acadêmico habitual. O texto foi apresentado, em geral, no formato de respostas a quesitos formulados pelas partes envolvidas, acompanhadas de introdução, informações complementares e conclusão. Ao rigor científico, geralmente exigido nos trabalhos acadêmicos, foi acrescido um forte compromisso com a ética na pesquisa e com a verdade dos fatos, pois o resultado desse trabalho pode influenciar uma decisão que afetará a vida de milhares de seres humanos, índios e não índios, habitantes na região. Assim, discursos retóricos, muitas vezes presentes em trabalhos de outra natureza, foram deixados de lado em nome do rigor científico e da clareza nas respostas aos quesitos. A linguagem impressa no laudo pericial demonstra que o texto foi produzido para operadores do direito, mas nem por isso é um 'documento' menos importante para etno-historiadores, antropólogos, arqueólogos, geógrafos e outros profissionais de áreas afins tomarem ciência do tema.

O principal objetivo de um trabalho como esse é dizer se a terra é ou não de ocupação tradicional indígena. Para a sua concretização, os autores valeram-se de metodologias reconhecidamente válidas pela comunidade científica nacional e internacional. Elenca-se, por exemplo, o recurso à etnografia por meio de observação direta, estudos genealógicos, histórias de vida, etno-história, documentação arquivística e história oral. Ao longo do texto verifica-se que os procedimentos foram aplicados com desenvoltura e respeito ético quando se referem a pessoas, tanto indígenas como regionais não indígenas. 
A partir das respostas formuladas aos quesitos, observa-se que, até a atualidade, mesmo o órgão da União responsável pela política indigenista oficial ainda utiliza com imprecisão conceitos relacionados ao problema. Daí verificar-se, por exemplo, a confusão entre aldeia, território indígena e terra indígena, conceitos que, somados a outros, foram esclarecidos, proporcionando ao juízo, o primeiro interessado, e agora a todos os leitores clareza acerca de seus significados. Clareza essa necessária para a boa compreensão de documentos históricos que, se mal interpretados (muitas vezes a má interpretação é proposital), podem trazer sérios prejuízos às partes litigantes.

De um modo geral, o texto permite perceber que a comunidade indígena em questão foi vítima, na década de 1950, de um processo de esbulho territorial empreendido pelos primeiros grandes proprietários da área, que receberam a titularidade das terras do estado de Mato Grosso. Os autores constataram, ainda, que nesse processo os proprietários contaram com o apoio de aparelhos do Estado e com a omissão dos órgãos indigenistas oficiais, inicialmente o Serviço de Proteção ao Índio (SPI) e depois a sua sucessora, a Funai. Tal processo de esbulho limitou a comunidade a uma pequena área junto ao distrito de Campestre e foi implementado por meio da intimidação e do uso de violência, chegando até mesmo à prática de homicídios. Foi ali que, em 1983, o líder indígena Marcal de Souza - Tupã'i - foi assassinado por ter atuado à frente das reivindicações territoriais dos Kaiowa em Mato Grosso do Sul.

Observa-se ainda que a estratégia de contestação, por parte dos proprietários das áreas incluídas na demarcação, gira em torno da reprodução de discursos já há muito desconstruídos no âmbito acadêmico. Insinua-se, por exemplo, que os Kaiowa de Ñande Ru Marangatu são índios paraguaios, situação que poderia limitar seus direitos no Brasil. Tal insinuação é desmentida pelos peritos, ao constatarem que muitos indígenas da comunidade em questão foram obrigados a migrar para o outro lado da fronteira, onde, contiguamente à fronteira, há uma terra indígena demarcada há várias décadas. Ao retornarem ao Brasil, foram propositalmente taxados como índios paraguaios, numa tentativa de privá-los dos direitos constitucionais garantidos pela Carta de 1988. Isso sem contar que um grupo de famílias fortemente ligadas ao núcleo de liderança política da comunidade nunca deixou a localidade, permanecendo no distrito rural de Campestre, incluído no perímetro da terra indígena. Além disso, verifica-se que é próprio da cultura desse povo o estabelecimento de laços de parentesco por vias de casamentos entre membros de diferentes comunidades. A situação inclui comunidades da mesma etnia situadas no país vizinho, sobretudo porque as fronteiras nacionais são artificiais e não evitaram, quando de sua demarcação, a divisão de comunidades pertencentes ao mesmo grupo étnico. Outra insinuação frequente é a de que, por trás das mobilizações indígenas, existe a manipulação de ONGs ou organizações similares e de alguns indigenistas e antropólogos. Tal insinuação trata os indígenas como pessoas que precisam ser submetidas a um poder tutelar, presumindo-se que permanecem numa espécie de infância eterna, o que já foi rebatido por inumeráveis estudos históricos e antropológicos.

Em suma, a perícia constatou que a área é importante para a garantia da reprodução física e cultural da comunidade. Percebe-se que o território favoreceria uma territorialização 
mais adequada à cultura daquele povo, aliviando-os dos problemas sociais que o afligem. Além disso, constata-se que na área se encontra um importante centro religioso guarani, o cerro marangatu, local repleto de significados religiosos, portanto essencial para as práticas religiosas daquela cultura. A perícia informa ainda que, com certeza, o intenso uso da terra para atividades agropastoris muito descaracterizou a área no que diz respeito aos seus recursos naturais, todavia argumenta que a cultura kaiowa, com seu dinamismo próprio, certamente terá condições de se adaptar às novas configurações. Acrescente-se a isso o fato de a recuperação ambiental não só ser possível como fazer parte dos objetivos de muitos indígenas que interagiram com os peritos.

É importante ressaltar que nos últimos anos, só em Mato Grosso do Sul, mais de dez perícias da mesma natureza foram produzidas. No entanto, essa é a primeira publicada em formato de livro. Tal feito tem a relevância de um trabalho inédito, que certamente contribuirá para aqueles envolvidos com pesquisas da mesma natureza. A publicação também é importante por ser exemplo de um trabalho técnico em que os conhecimentos cientificamente produzidos podem ser aplicados em solução de demandas socialmente relevantes. Certamente pode servir de referência para cientistas sociais, estudantes, juristas e povos indígenas em contendas de teor semelhante, que infelizmente, na atual conjuntura, se estenderão ainda por muitos anos.

Para concluir, ressaltamos que os autores do livro, mesmo sem tocar diretamente no assunto, inspiram os leitores a pensar sobre os aspectos éticos da atuação dos cientistas sociais. Nota-se o compromisso dos peritos com a lisura e isenção, respaldadas em sólida formação acadêmica. Por outro lado, percebe-se que as tentativas, por parte dos assistentes técnicos dos proprietários, de invalidar o estudo realizado pelo GT da Funai são orientadas por profissionais com formação em ciências humanas, porém não antropólogos - portanto não dominam as teorias e métodos antropológicos. É evidente que o trabalho dos assistentes não é necessariamente ilegítimo ou antiético, contudo é preciso uma reflexão de natureza ética quando trabalhos dessa natureza são fruto da deturpação de fontes históricas e dados etnológicos, fato observado com frequência. Diante de tais questões, percebe-se que a atuação dos profissionais das ciências humanas é cada vez mais decisiva e estrategicamente relevante, e por isso deve ser pautada por uma conduta ética e de resistência a pressões políticas e financeiras - de modo a garantir lisura e imparcialidade - e apoiar-se em métodos reconhecidos pela comunidade científica nacional e internacional.

\section{NOTAS}

* O presente trabalho foi realizado com apoio do CNPq, Conselho Nacional de Desenvolvimento Científico e Tecnológico - Brasil.

${ }^{1}$ Em seu ápice territorial, a Mate Larangeira teve o maior arrendamento de terras públicas do período republicano. Com o decreto 520, de 15 de julho de 1895, seus domínios alcançaram mais de cinco milhões de hectares.

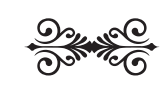

